\title{
Ranitidine reduced levodopa-induced dyskinesia in a rat model of Parkinson's disease
}

This article was published in the following Dove Press journal:

Neuropsychiatric Disease and Treatment

18 December 2013

Number of times this article has been viewed

\section{Guiyun Cuil,* \\ Xinxin Yangl,* \\ Xiaoying Wang ${ }^{2, *}$ \\ Zunsheng Zhang' \\ Xuanye Yue' \\ Hongjuan Shi' \\ Xia Shen'}

'Department of Neurology, ${ }^{2}$ Department of Ultrasound, the Affiliated Hospital of Xuzhou Medical College, Jiangsu, People's Republic of China

*These authors contributed equally to this work
Correspondence: Xinxin Yang Department of Neurology, the Affiliated Hospital of Xuzhou Medical College, 99 West Huaihai Road, Xuzhou 221000, Jiangsu, People's Republic of China

Tel +8651685802306

Fax +8651685802306

Email neurologyang@126.com
Background: Chronic administration of levodopa in Parkinson's disease leads to debilitating involuntary movements, termed levodopa-induced dyskinesia (LID). The pathogenesis of LID is poorly understood. Previous research has shown that histamine $\mathrm{H}_{2}$ receptors are highly expressed in the input (striatum) and output (globus pallidus, substantia nigra) regions of the basal ganglia, particularly in the GABAergic striatopallidal and striatonigral pathways. Therefore, a histamine $\mathrm{H}_{2}$ receptor antagonist could be used to reduce LID. In the present work, we investigated whether ranitidine has the potential to diminish LID in rats with dyskinesia and explored the underlying mechanisms involved.

Methods: A rat model of PD was induced by 6-hydroxydopamine. Valid PD rats were then treated with levodopa $(25 \mathrm{mg} / \mathrm{kg}$, intraperitoneally) and benserazide $(12.5 \mathrm{mg} / \mathrm{kg}$, intraperitoneally) for 21 days to induce a rat model of LID. The acute and chronic effects of administration of ranitidine at different doses $(5 \mathrm{mg} / \mathrm{kg}, 10 \mathrm{mg} / \mathrm{kg}$, and $20 \mathrm{mg} / \mathrm{kg}$ ) on abnormal involuntary movements, levodopa-induced rotations, and the forelimb adjusting steps test were investigated in LID rats. The chronic effect of ranitidine $(10 \mathrm{mg} / \mathrm{kg})$ on the expression of Arc and proenkephalin was also evaluated.

Results: Levodopa elicited increased dyskinesia in PD rats. Acute ranitidine treatment had no effect on LID, but chronic ranitidine administration $(10 \mathrm{mg} / \mathrm{kg}, 20 \mathrm{mg} / \mathrm{kg}$ ) reduced LID in rats with dyskinesia. Importantly, levodopa-induced rotations were not affected by chronic treatment with ranitidine. In addition, chronic ranitidine $(10 \mathrm{mg} / \mathrm{kg}, 20 \mathrm{mg} / \mathrm{kg})$ significantly improved stepping of the lesioned forepaw. Real-time polymerase chain reaction showed that Arc and proenkephalin levels were reduced by chronic ranitidine $(10 \mathrm{mg} / \mathrm{kg})$ in dyskinetic rats.

Conclusion: These data indicate that ranitidine is a good adjunct for reducing LID in rats with dyskinesia. Inhibition of dopamine D1-mediated activation in the medium spiny neurons may account for the antidyskinetic effects of ranitidine in rats with dyskinesia.

Keywords: Parkinson's disease, levodopa-induced dyskinesia, ranitidine, Arc, proenkephalin

\section{Introduction}

Parkinson's disease (PD) is a neurodegenerative disorder characterized by progressive loss of dopaminergic neurons in the substantia niagra. ${ }^{1} \mathrm{PD}$ is the second most common neurologic disease after Alzheimer's disease, and 30\%-50\% of PD patients suffer from levodopa-induced dyskinesia (LID) after administration of levodopa for 5-10 years. ${ }^{2}$ Levodopa remains the most effective drug for the treatment of PD. ${ }^{3,4}$ Unfortunately, with disease progression, levodopa reduces parkinsonism at the cost of evoking abnormal involuntary movements (AIMS), ie, LID. ${ }^{5,6}$ Until now, the pathogenesis of LID remains poorly understood. 
As we known, dopaminergic nigrostriatal depletion accompanied by the unique pharmacokinetics and action of levodopa. Pulsatile dopamine stimulation plays a key role in development of LID, and can induce overexpression of immediate early genes such as Arc and proenkephalin (Penk) in levodopa-primed PD rats, as we have previously reported. ${ }^{7}$ The resulting changes in corticostriatal transmission and plastic synaptic abnormalities in striatal spiny neurons may alter the physiological activity of the striatopallidal circuits, leading to an abnormal pattern of neuronal activity. The strategy used to treat LID is reduction of dopaminergic stimulation. However, this has the potential to worsen parkinsonism in PD. Bilateral subthalamic nucleus deep brain stimulation is effective in ameliorating LID, and allows reduction of the dose of levodopa. Thus, expression of LID in PD is reduced. However, not all patients are suitable for surgery, so an adjunctive drug such as amantadine is used to treat LID. Although LID in PD is attenuated by amantadine, ${ }^{8}$ the drug can only provide short-term benefits in the treatment of the condition. ${ }^{9}$ For this reason, we need to find other drugs for the treatment of PD. Recent studies have shown that one potential target is the histamine system. For example, Johnston et al reported that famotidine could reduce LID in the 1-methyl-4-phenyl-1,2,3,6-tetrahydropyridine (MPTP)lesioned macaque model of Parkinson's disease. ${ }^{10}$ As we know, the central histaminergic system is involved in diverse biological functions, including thermoregulation, eating, and sleep. A role in motor activity is suggested by strong histaminergic innervation of the basal ganglia. ${ }^{11,12}$ Histamine exerts its effects through four receptor subtypes, ie, $\mathrm{H}_{1}-\mathrm{H}_{4} \cdot{ }^{13}$
However, only histamine $\mathrm{H}_{2}$ and $\mathrm{H}_{3}$ receptors are closely correlated with expression of LID. Histamine $\mathrm{H}_{2}$ receptors are highly expressed in the input (striatum) and output (globus pallidus, substantia nigra) regions of the basal ganglia. ${ }^{14}$ More importantly, the histamine $\mathrm{H}_{2}$ receptor modulates dopamine D1-mediated activation by decreasing acetylcholine levels in the direct pathway. ${ }^{15} \mathrm{~A}$ limited number of studies have investigated the effect of $\mathrm{H}_{2}$ receptor antagonists on LID. Here we report on chronic administration of ranitidine, a histamine $\mathrm{H}_{2}$ receptor antagonist, that could be used to alleviate LID in levodopa-primed PD rats.

\section{Materials and methods Experimental protocol}

6-hydroxydopamine (OHDA) injections were used to produce a rat model of PD. After 3 weeks of injections, rats showing stable apomorphine-induced rotations (more than seven turns per minute) were selected as valid PD rats and treated with levodopa plus benserazide twice daily for 21 days. In the first experiment (Figure 1A), dyskinetic rats were divided into three groups and treated with ranitidine at different doses ( $5 \mathrm{mg} / \mathrm{kg}, 10 \mathrm{mg} / \mathrm{kg}$, and $20 \mathrm{mg} / \mathrm{kg}$ ) or vehicle 5 minutes before administration of levodopa $(25 \mathrm{mg} / \mathrm{kg}$ plus benserazide $12.5 \mathrm{mg} / \mathrm{kg}$, both intraperitoneally). AIMS scores and rotations were measured at 20, 40, 60, 80, 100, 120, 140, 160, and 180 minutes after treatment. In the second experiment (Figure 1B), dyskinetic rats were divided into three groups and treated with ranitidine at different doses $(5 \mathrm{mg} / \mathrm{kg}, 10 \mathrm{mg} /$ $\mathrm{kg}$, and $20 \mathrm{mg} / \mathrm{kg}$ ) or vehicle 5 minutes before administration of levodopa $(25 \mathrm{mg} / \mathrm{kg}$ plus benserazide $12.5 \mathrm{mg} / \mathrm{kg}$, both
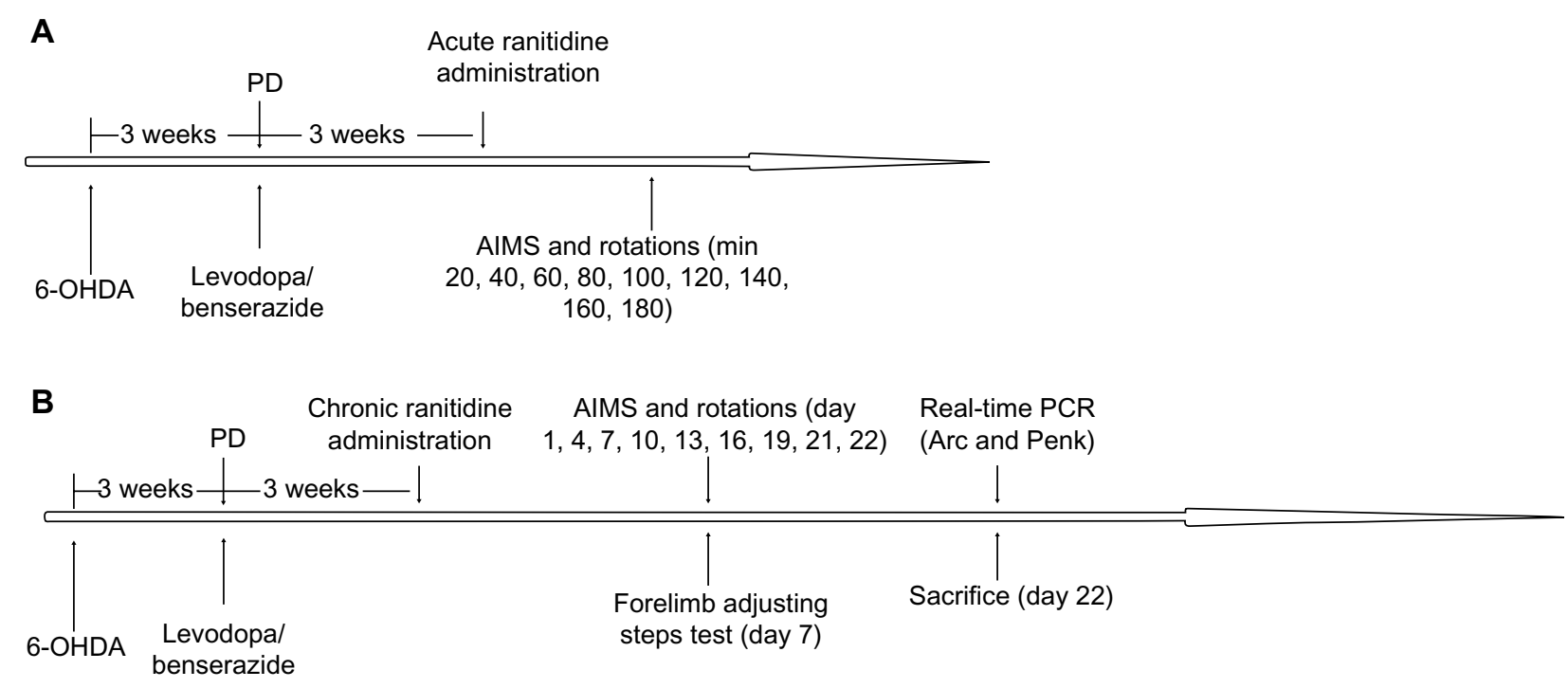

Figure I Protocol for the experiment. (A) Acute and (B) chronic ranitidine administration in dyskinetic rats.

Abbreviations: AIMS, abnormal involuntary movements; PD, Parkinson's disease; 6-OHDA, 6-hydroxydopamine; PCR, polymerase chain reaction. 
intraperitoneally) daily for 22 days. AIMS scores and rotations were measured at days 1, 4, 7, 10, 13, 16, 19, 21 and 22 of treatment. The forelimb adjusting steps test was performed on day 7 of treatment. On day 22, all rats were sacrificed after their last behavioral test, and Penk and Arc levels in the striatum were measured by real-time polymerase chain reaction $(\mathrm{PCR})$.

\section{Animals}

Ninety-five adult rats (Sprague-Dawley females, 180-220 g) were used in this study. All protocols involving these animals were performed according to the guidelines of the National Institutes of Health for the Care and Use of Laboratory Animals.

\section{Lesions}

All animals received injections containing $8 \mu \mathrm{g}$ of 6-OHDA (dissolved in $4 \mu \mathrm{L}$ of $0.9 \%$ physiologic saline containing $0.02 \%$ ascorbic acid; Sigma-Aldrich, St Louis, MO, USA) into the right medial forebrain bundle. The coordinates used were in accordance with an atlas of the rat brain ${ }^{16}$ (bregma $4.5 \mathrm{~mm}$; lateral $0.9 \mathrm{~mm}$; dura $7.5 \mathrm{~mm}$ ). Three weeks after the injections, rats showing stable apomorphine-induced rotational asymmetry of at least seven full turns per minute away from the lesioned side were selected for the next experiment. It has been demonstrated that rats manifesting this circling behavior display more than $90 \%$ depletion of striatal dopamine. ${ }^{17}$

\section{Treatment}

Valid PD rats were treated with levodopa $(25 \mathrm{mg} / \mathrm{kg}$ plus benserazide $12.5 \mathrm{mg} / \mathrm{kg}$, both intraperitoneally) daily for 21 days. Animals not developing moderate AIMS were excluded from the study (total AIMS $\leq 30$ on day 7). In total, 56 rats met the criteria. Twenty-eight rats were involved in each experiment. In the first experiment, the effects of acute ranitidine administration on LID and levodopa-induced rotations in rats with dyskinesia were assessed. The dyskinetic rats were divided into three groups and treated with ranitidine at different doses $(5 \mathrm{mg} / \mathrm{kg}, 10 \mathrm{mg} /$ $\mathrm{kg}$, and $20 \mathrm{mg} / \mathrm{kg}$ ) or vehicle 5 minutes before administration of levodopa ( $25 \mathrm{mg} / \mathrm{kg}$ plus benserazide $12.5 \mathrm{mg} / \mathrm{kg}$, intraperitoneally). In the second experiment, the effects of chronic ranitidine administration on LID and levodopa-induced rotations in rats with dyskinesia were assessed. As in the first experiment, rats with dyskinesia were divided into three groups and treated with ranitidine at different doses $(5 \mathrm{mg} / \mathrm{kg}, 10 \mathrm{mg} / \mathrm{kg}$, and $20 \mathrm{mg} / \mathrm{kg})$ or vehicle 5 minutes before administration of levodopa $(25 \mathrm{mg}$ / $\mathrm{kg}$ plus benserazide $12.5 \mathrm{mg} / \mathrm{kg}$, both intraperitoneally) daily for
22 days. Immediately after treatment, the rats were monitored for AIMS and rotations for 180 minutes. All investigators were blinded to the treatment and the behavioral tests.

\section{Abnormal involuntary movements}

Rats were monitored for AIMS using a previously reported procedure. ${ }^{18}$ On test days, the rats were individually placed in plastic trays 5 minutes before drug treatment. Following injection, each rat was assessed for axial, limb, orolingual, and locomotor movements. At 20-minute intervals (ie, from 20, 40, 60, 80 minutes onwards), AIMS were rated over 60 seconds in each rat for a total of 180 minutes, during which time a severity score of $0-4$ was assigned for each AIMS category. A score of 0 was assigned for the absence of AIMS; 1 for occasional AIMS ( $<50 \%$ of observation time); 2 for frequent AIMS ( $>50 \%$ of observation time); 3 for AIMS that were continuous but interrupted by strong sensory stimuli; and 4 for continuous, uninterrupted AIMS. For each AIMS category, the scores were summed for each time point.

\section{Forelimb adjusting steps test}

The stepping test was performed as previously described. ${ }^{19}$ Briefly, the rat was held by the experimenter, fixing the hind limbs with one hand and the forelimb not to be monitored with the other, while the unrestrained forepaw was touching the table. The number of adjusting steps was counted for both forelimbs while the rat was moved sideways along the table surface ( $90 \mathrm{~cm}$ in 5 seconds) in the forward and backward directions, and the average of the steps in the two directions was recorded. Performance of the animals in the stepping test was assessed on treatment day 7, as shown in Figure 1B.

\section{Real-time PCR}

Arc and Penk levels were measured by real-time PCR, as previously reported. ${ }^{7}$ The rats were sacrificed by deep anesthesia after their last behavioral test, after which striatal tissues from the sham and 6-OHDA-lesioned rats treated with vehicle or pulsatile levodopa alone or in combination with ranitidine were homogenized, and total RNA was extracted using Trizol reagent (Life Technologies, Carlsbad, CA, USA). The primer sequences used in this study were as follows: 5'-CTGCCACAGAAGCAGGGTGA-3' (forward) and 5'-AGGGTGCCCACCACATACTGA-3' (reverse) for Arc; 5'-TGGCTACAGTGCAGGCAGA-3' (forward) and 5'-TTGTACATGTCGATGTTATCCCAAG-3' (reverse) for Penk. The PCR amplifications were performed using 50 cycles of denaturation at $95^{\circ} \mathrm{C}$ for 15 seconds, with annealing at $60^{\circ} \mathrm{C}$ for 30 seconds and extension at $72^{\circ} \mathrm{C}$ for 

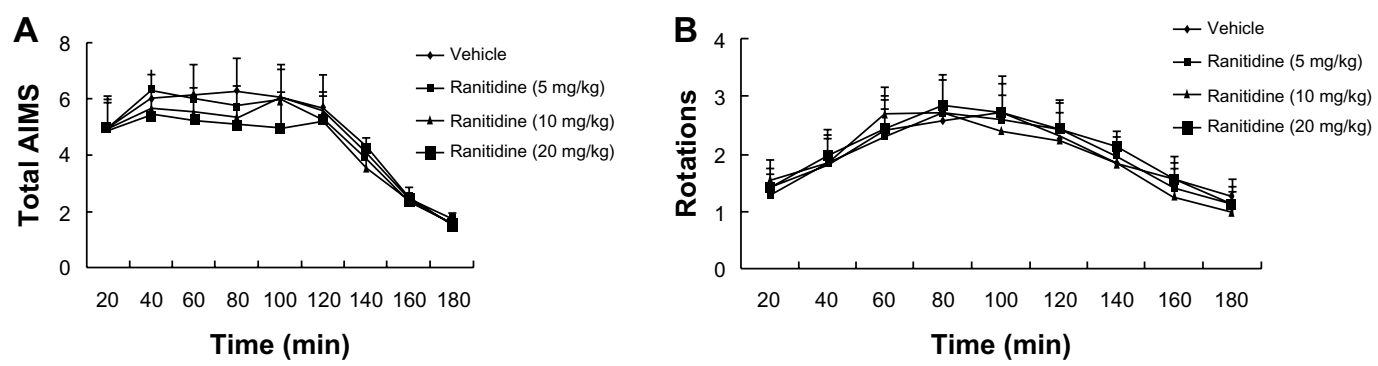

Figure 2 Effects of acute ranitidine administration on axial/limb/orolingual AIMS and rotations in levodopa (25 mg/kg) + benserazide (I2.5 mg/kg)-primed, hemiparkinsonian rats $(n=7)$.

Abbreviation: AIMS, abnormal involuntary movements.

20 seconds using the ABI 7300 Real-Time PCR System (Life Technologies). The results are shown as relative expression corrected to the house-keeping gene $\beta$-actin.

\section{Data analysis}

The data are expressed as the mean \pm standard error of the mean. AIMS and rotations were analyzed by two-way repeated-measures analysis of variance followed by the Bonferroni post hoc. Forelimb adjusting steps and Arc and Penk levels were analyzed by one-way analysis of variance followed by the Newman-Keuls post hoc test. A $P$-value less than 0.05 was considered to be statistically significant.

\section{Results}

\section{Effects of acute ranitidine administration on levodopa-induced AIMS and rotations}

As shown in Figure 2A, pulsatile administration of levodopa in PD rats induced increased expression of LID. Acute administration of ranitidine at different doses $(5 \mathrm{mg} / \mathrm{kg}, 10 \mathrm{mg} / \mathrm{kg}$, and $20 \mathrm{mg} / \mathrm{kg}$ ) had no obvious effect on expression of LID in the dyskinetic rats. As shown in Figure 2B, there was a significant effect of time on levodopa-induced rotations. Acute ranitidine administration at different doses $(5 \mathrm{mg} / \mathrm{kg}$,
$10 \mathrm{mg} / \mathrm{kg}$, and $20 \mathrm{mg} / \mathrm{kg}$ ) had no effect on levodopa-induced rotations in the dyskinetic rats.

\section{Effects of chronic ranitidine administration on levodopa-induced AIMS and rotations}

Three doses of ranitidine $(5 \mathrm{mg} / \mathrm{kg}, 10 \mathrm{mg} / \mathrm{kg}$, and $20 \mathrm{mg} / \mathrm{kg}$ ) were tested in levodopa-primed rats to determine their effects on AIMS and rotations. As shown in Figure 3A, intermittent administration of levodopa induced LID in 6-OHDA-lesioned rats. However, chronic administration of ranitidine $(10 \mathrm{mg} /$ $\mathrm{kg}$ and $20 \mathrm{mg} / \mathrm{kg}$ ) with levodopa reduced the expression of LID in the dyskinetic rats. The $5 \mathrm{mg} / \mathrm{kg}$ dose of ranitidine had no effect. These data indicate that ranitidine could be used to reduce the expression of LID in rats with dyskinesia, but only at a high dose. Moreover, there was no difference in AIMS between the $10 \mathrm{mg}$ ranitidine group and $20 \mathrm{mg}$ ranitidine group, indicating that $10 \mathrm{mg} / \mathrm{kg}$ is an appropriate dose for reducing LID in levodopa-primed PD rats. Numbers of levodopa-induced rotations were then measured. As shown in Figure 3B, the different doses of ranitidine $(5 \mathrm{mg} / \mathrm{kg}$, $10 \mathrm{mg} / \mathrm{kg}$, and $20 \mathrm{mg} / \mathrm{kg}$ ) had no effect on levodopa-induced rotations.
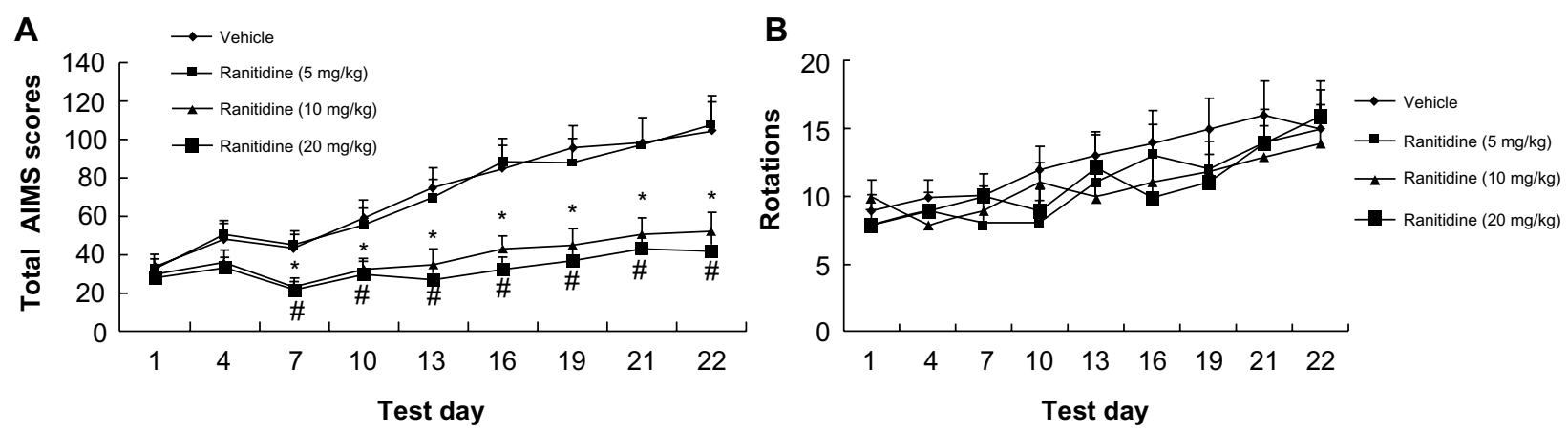

Figure 3 Effects of chronic ranitidine administration on AIMS and rotations in seven hemiparkinsonian rats primed with levodopa ( $25 \mathrm{mg} / \mathrm{kg})+$ benserazide ( $12.5 \mathrm{mg} / \mathrm{kg})$. Notes: $* P<0.05$ versus vehicle; ${ }^{*}<<0.0$ I versus vehicle. AIMS were analyzed by two-way repeated-measures analysis of variance, followed by the Bonferroni post hoc test. Rotations were analyzed by two-way analysis of variance, followed by the Bonferroni post hoc test.

Abbreviation: AIMS, abnormal involuntary movements. 


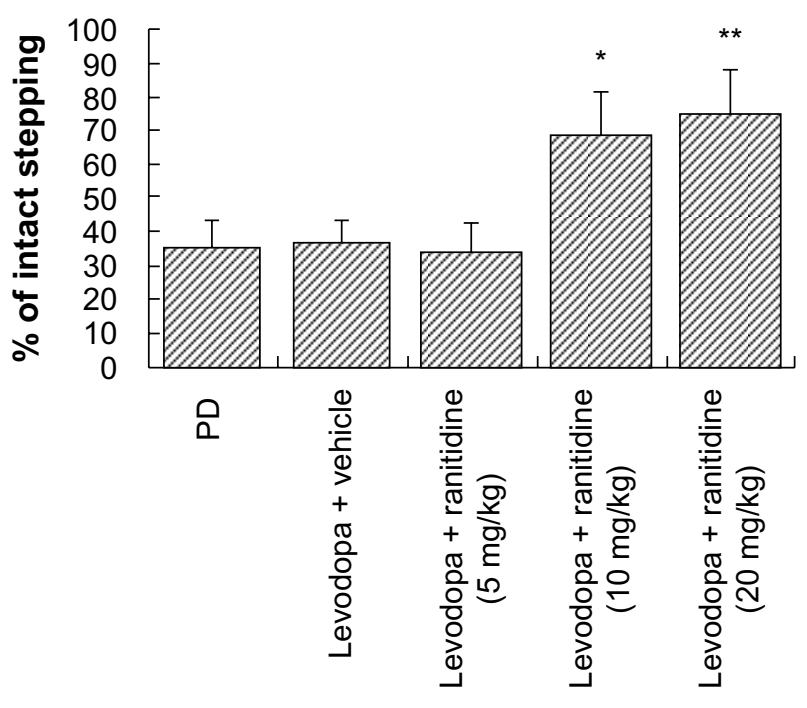

Figure 4 Effects of ranitidine on motor performance in the forepaw adjusting steps test in seven hemiparkinsonian rats primed with levodopa $(25 \mathrm{mg} / \mathrm{kg})+$ benserazide $\left(\right.$ I $2.5 \mathrm{mg} / \mathrm{kg}$ ). $* P<0.05$, versus levodopa + vehicle group; ${ }^{*} * P<0.0$ I versus levodopa + vehicle group. The data were analyzed by one-way analysis of variance, followed by the Newman-Keuls post hoc test.

Abbreviation: PD, Parkinson's disease.

\section{Effects of ranitidine on motor performance}

The forelimb adjusting steps test was used to determine whether a high dose of ranitidine $(10 \mathrm{mg} / \mathrm{kg})$ affects the therapeutic efficacy of levodopa. As shown in Figure 4, treatment with ranitidine plus levodopa significantly improved stepping of the lesioned forepaw in PD rats. There were no significant treatment effects from ranitidine on intact forepaw stepping (data not shown).

\section{Coadministration of ranitidine and levodopa prevented increases in Arc and Penk in levodopa-treated PD rats}

Arc and Penk levels were measured by real-time PCR. As shown in Figure 5, Arc and Penk were increased in 6-OHDA-lesioned rats. Pulsatile levodopa treatment induced a further increase of Arc and Penk in these rats. In contrast, treatment with ranitidine $10 \mathrm{mg} / \mathrm{kg}$ prevented the increase in Arc and Penk in PD rats treated long term with levodopa.

\section{Discussion}

From our study, we found that: acute administration of ranitidine had no effect on expression of dyskinesia induced by levodopa in dyskinetic rats; chronic treatment with ranitidine reduced the expression of LID and improved stepping of the lesioned forepaw without affecting the antiparkinsonian effect of levodopa in dyskinetic rats; and chronic treatment with ranitidine depressed Arc and Penk levels in the striatal tissue of levodopa-primed rats.

Dopamine denervation is the pathologic hallmark of PD. Levodopa remains the most effective drug in the treatment of the disease. However, LID is a severe complication caused by levodopa. ${ }^{20,21}$ In the present study, we found that treatment with levodopa induced full LID expression in PD rats, including axial, forelimb, orolingual, and locomotor dyskinesia, as demonstrated by increased AIMS over 22 days. Acute administration of ranitidine had no effect on LID. However, chronic administration of ranitidine could reduce established LID, but only at a high dose. This indicates that although established LID is difficult to treat, long-term treatment with ranitidine has the potential to reverse it. The forelimb adjusting steps test was used to determine whether administration of ranitidine affects the therapeutic efficacy of levodopa. We found that treatment with ranitidine plus levodopa significantly improved stepping of the lesioned forepaw in PD rats, suggesting that ranitidine may be a good adjunct for reducing LID. We note previous studies in humans showing that chronic treatment with ranitidine can induce movement disorders such as dystonia and chorea, ${ }^{22,23}$ which seems to be inconsistent with the findings of our study. We believe that this discrepancy was because ranitidine was given to different subjects.

The precise pathophysiology of LID remains unclear. Previous research has demonstrated that the histamine $\mathrm{H}_{2}$ receptor is involved in expression of LID. ${ }^{10}$ Histamine via $\mathrm{H}_{2}$ receptors indirectly increases the firing frequency of projection neurons in the substantia nigra pars reticulate, so may contribute to the overactive basal ganglia output in $\mathrm{PD}^{24}$ Therefore, $\mathrm{H}_{2}$ antagonists could potentially act synergistically with levodopa to reduce overactivity of the substantia nigra pars reticulata. Previous studies have also indicated that $\mathrm{H}_{2}$ antagonists have the ability to modulate striatal release of acetylcholine. ${ }^{25,26}$ Moreover, histamine $\mathrm{H}_{2}$ receptor stimulation decreases acetylcholine in the striatum and then reduces dopamine D1-mediated activation, leading to increased activity in the direct striatal output pathway. ${ }^{15}$ As we know, D1-mediated activation is closely correlated with LID. Further, a previous study showed that famotidine, a type of histamine $\mathrm{H}_{2}$ receptor antagonist, could reduce LID in the MPTP-lesioned macaque model of PD. ${ }^{10}$ Therefore, we assumed that histamine $\mathrm{H}_{2}$ may be involved in the expression of LID, and that modulation of the histamine $\mathrm{H}_{2}$ receptor may affect this. In our study, we found that chronic treatment with ranitidine reduced established LID without affecting the antiparkinsonian effect of levodopa, which confirmed our assumption. 


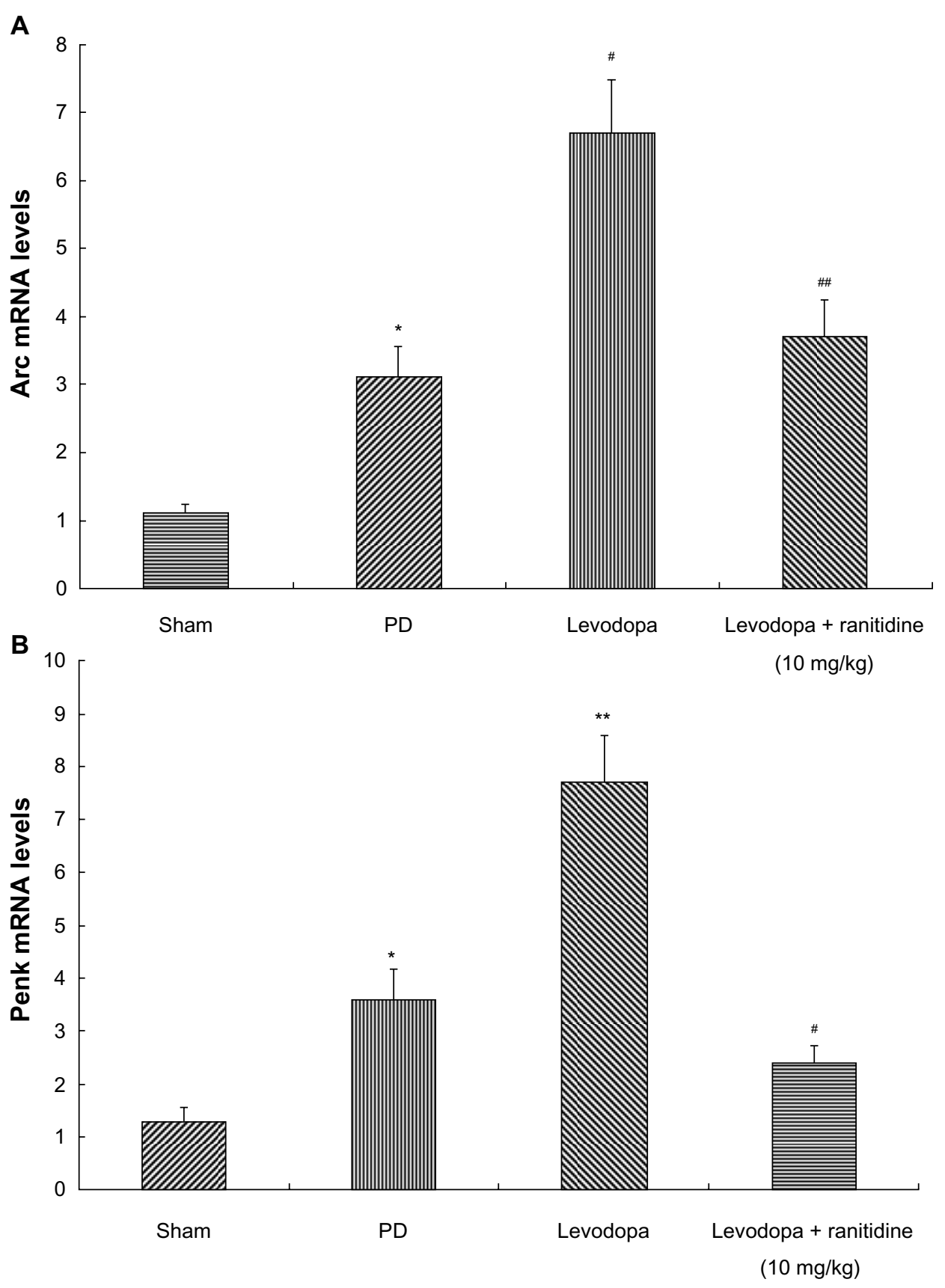

Figure 5 Treatment with ranitidine prevented an increase in Arc and Penk. Arc and Penk levels were increased in PD rats. Repeated levodopa treatment induced further increased expression of Arc and Penk levels. Conversely, ranitidine prevented the increase of Arc and Penk (seven rats per group). (A) $* P<0.05$ versus sham group; ${ }^{\#} P<0.0$ l versus PD group; $P<0.0$ I versus levodopa group. (B) $* P<0.05$ versus sham group; $* * P<0.01$ versus $P D$ group; ${ }^{*} P<0.05$ versus levodopa group. The data were analyzed by one-way analysis of variance, followed by the Newman-Keuls post hoc test.

Abbreviations: PD, Parkinson's disease; mRNA, messenger RNA.

It is well known that dopamine depletion results in enhanced responsiveness of striatal neurons in the direct striatonigral pathway after intermittent administration of levodopa. Previous studies have demonstrated that the ability of dopamine to stimulate adenylyl cyclase and protein kinase A via activation of the D1 receptor is enhanced in the rat model of $\mathrm{PD},{ }^{27}$ which may represent a compensation for the lack of striatal dopamine. LID can be evoked by persistent hyperactivation of cAMP/PKA signaling in medium spiny neurons. ${ }^{28-30}$ cAMP-regulated phosphoprotein of molecular mass 32,000 (DARPP-32) is one of the important mediators of cAMP signaling, and is well known to play a critical role in D1R-mediated transmission. ${ }^{31}$ It is now well established that phosphorylation of DARPP-32 at threonine 34 may have important consequences in the increased expression of LID. ${ }^{32-34}$ One possible mechanism by which DARPP-32 
participates in changes in the early gene expression associated with LID is to induce early gene expression of, eg, $\Delta$ FosB, and regulate the state of phosphorylation of two mitogenactivated protein kinases, ie, extracellular signal-regulated kinases 1 and 2 (ERK1 and ERK2, respectively). ${ }^{35}$

Based on the discussion above, we can draw the conclusion that phospho-DARPP-32-Thr34 and phosphorylated ERK1/2 play an important role in the expression of LID. Importantly, p-DARPP-32 and p-ERK1/2 induce expression of immediate early genes, such as Arc and Penk, in dyskinetic rats, as we have previously reported. ${ }^{7}$ Striatal dynorphin levels are then increased in PD rats after activation of these two genes. ${ }^{36}$ As we know, dynorphin is closely correlated with expression of LID. ${ }^{7}$ In the present study, long-term treatment with levodopa induced an increase in Arc and Penk levels. However, chronic administration of ranitidine could reduce Arc and Penk expression in rats with established PD, which may account for the antidyskinetic effect of ranitidine.

Taken together, we have shown that a significant proportion of motor complications in PD occurs subsequent to a persistently sensitized response to levodopa and upregulation of the protein kinase A-mediated signaling pathway. However, chronic administration of ranitidine reduced the expression of LID in rats with dyskinesia. Inhibition of dopamine D1-mediated activation in the direct pathway may account for the antidyskinetic effects of ranitidine in these rats.

\section{Acknowledgment}

The study was supported by the National Natural Science Foundation of China (No 81301077 and No 81271344), the Natural Science Foundation of Jiangsu Higher Education Institutions (13KJB320026), and the Summit of Six Top Talents Program of Jiangsu Province to Dr Cui.

\section{Disclosure}

The authors report no conflicts of interest in this work.

\section{References}

1. Sherer TB, Betarbet R, Greenamyre JT. Pathogenesis of Parkinson's disease. Curr Opin Investig Drugs. 2001;2:657-662.

2. Yang $\mathrm{X}, \mathrm{Wu} \mathrm{N}$, Song L, Liu Z. Intrastriatal injections of KN-93 ameliorates levodopa-induced dyskinesia in a rat model of Parkinson's disease. Neuropsychiatr Dis Treat. 2013;9:1213-1220.

3. Eskow KL, Dupre KB, Barnum CJ, Dickinson SO, Park JY, Bishop C. The role of the dorsal raphe nucleus in the development, expression, and treatment of LID in hemiparkinsonian rats. Synapse. 2009;63: 610-620.

4. Jankovic J. Parkinson's disease therapy: treatment of early and late disease. Chin Med J. 2001;114:227-234.
5. Jaunarajs KL, Dupre KB, Steiniger A, et al. Serotonin 1B receptor stimulation reduces D1 receptor agonist-induced dyskinesia. Neuroreport. 2009;20:1265-1269.

6. Carta M, Carlsson T, Kirik D, Björklund A. Dopamine released from 5-HT terminals is the cause of L-DOPA-induced dyskinesia in parkinsonian rats. Brain. 2007;130:1819-1833.

7. Yang X, Chen Y, Hong X, et al. Levodopa/benserazide microspheres reduced levodopa-induced dyskinesia by downregulating phosphorylated GluR1 expression in 6-OHDA-lesioned rats. Drug Des Devel Ther. 2012;6:341-347.

8. Paquette MA, Martinez AA, Macheda T, et al. Anti-dyskinetic mechanisms of amantadine and dextromethorphan in the 6-OHDA rat model of Parkinson's disease: role of NMDA vs 5-HT1A receptors. Eur J Neurosci. 2012;36:3224-3234.

9. Elahi B, Phielipp N, Chen R. N-methyl-D-aspartate antagonists in levodopa induced dyskinesia: a meta-analysis. Can J Neurol Sci. 2012;39:465-472.

10. Johnston TH, van der Meij A, Brotchie JM, Fox SH. Effect of histamine $\mathrm{H} 2$ receptor antagonism on levodopa-induced dyskinesia in the MPTP-macaque model of Parkinson's disease. Mov Disord. 2010;25: $1379-1390$.

11. Anichtchik OV, Rinne JO, Kalimo H, Panula P. An altered histaminergic innervation of the substantia nigra in Parkinson's disease. Exp Neurol. 2000;163:20-30.

12. Rinne JO, Anichtchik OV, Eriksson KS, et al. Increased brain histamine levels in Parkinson's disease but not in multiple system atrophy. J Neurochem. 2002;81:954-960.

13. Parsons ME, Ganellin CR. Histamine and its receptors. Br J Pharmacol. 2006;147 Suppl 1:S127-S135.

14. Vizuete ML, Traiffort E, Bouthenet ML, et al. Detailed mapping of the histamine $\mathrm{H} 2$ receptor and its gene transcripts in guinea pig brain. Neuroscience. 1997;80:321-343.

15. Pisani A, Bernardi G, Ding J, Surmeier DJ. Re-emergence of striatal cholinergic interneurons in movement disorders. Trends Neurosci. 2007;30:545-553.

16. Paxinos G, Watson C. The Rat Brain in Stereotaxic Coordinates. San Diego, CA, USA: Academic Press; 2007.

17. Schwarting RK, Huston JP. The unilateral 6-hydroxydopamine lesion model in behavioral brain research. Analysis of functional deficits, recovery and treatments. Prog Neurobiol. 1996;50:275-331.

18. Carta M, Lindgren HS, Lundblad M, Stancampiano R, Fadda F, Cenci MA. Role of striatal L-DOPA in the production of dyskinesia in 6-hydroxydopamine lesioned rats. J Neurochem. 2006;96: $1718-1727$.

19. Ren T, Yang X, Wu N, Cai Y, Liu Z, Yuan W. Sustained-release formulation of levodopa methyl ester/benserazide for prolonged suppressing dyskinesia expression in 6-OHDA-leisoned rats. Neurosci Lett. 2011;502:117-122.

20. Ouattara B, Hoyer D, Grégoire L, et al. Changes of AMPA receptors in MPTP monkeys with levodopa-induced dyskinesias. Neuroscience. 2010;167:1160-1167.

21. Morissette M, Dridi M, Calon F, et al. Prevention of dyskinesia by an NMDA receptor antagonist in MPTP monkeys: effect on adenosine A2A receptors. Synapse. 2006;60:239-250.

22. Elzinga-Huttenga J, HeksterY, Bijl A, Rotteveel J. Movement disorders induced by gastrointestinal drugs: two paediatric cases. Neuropediatrics. 2006;37:102-106.

23. Kapur V, Barber KR, Peddireddy R. Ranitidine-induced acute dystonia. Am J Emerg Med. 1999;17:258-260.

24. Zhou FW, Xu JJ, Zhao Y, LeDoux MS, Zhou FM. Opposite functions of histamine $\mathrm{H} 1$ and $\mathrm{H} 2$ receptors and $\mathrm{H} 3$ receptor in substantia nigra pars reticulata. J Neurophysiol. 2006;96:1581-1591.

25. Prast $\mathrm{H}$, Tran $\mathrm{MH}$, Lamberti $\mathrm{C}$, et al. Histaminergic neurons modulate acetylcholine release in the ventral striatum: role of $\mathrm{H} 1$ and $\mathrm{H} 2$ histamine receptors. Naunyn Schmiedebergs Arch Pharmacol. 1999;360: $552-557$. 
26. Sittig N, Davidowa $H$. Histamine reduces firing and bursting of anterior and intralaminar thalamic neurons and activates striatal cells in anesthetized rats. Behav Brain Res. 2001;124:137-143.

27. Tong J, Fitzmaurice PS, Ang LC, Furukawa Y, Guttman M, Kish SJ. Brain dopamine-stimulated adenylyl cyclase activity in Parkinson's disease, multiple system atrophy, and progressive supranuclear palsy. Ann Neurol. 2004;55:125-129.

28. Aubert I, Guigoni C, Håkansson K, et al. Increased D1 dopamine receptor signaling in levodopa-induced dyskinesia. Ann Neurol. 2005;57:17-26.

29. Corvol JC, Muriel MP, Valjent E, et al. Persistent increase in olfactory type G-protein alpha subunit levels may underlie D1 receptor functional hypersensitivity in Parkinson disease. J Neurosci. 2004;24: 7007-7014.

30. Picconi B, Centonze D, Håkansson K, et al. Loss of bidirectional striatal synaptic plasticity in L-DOPA-induced dyskinesia. Nat Neurosci. 2003;6:501-506.
31. Greengard P. The neurobiology of slow synaptic transmission. Science. 2001;294:1024-1030

32. Sgambato-Faure V, Buggia V, Gilbert F, Lévesque D, Benabid AL, Berger F. Coordinated and spatial upregulation of arc in striatonigral neurons correlates with L-dopa-induced behavioral sensitization in dyskinetic rats. J Neuropathol Exp Neurol. 2005;64:936-947.

33. Svenningsson P, Fienberg AA, Allen PB, et al. Dopamine D(1) receptorinduced gene transcription is modulated by DARPP-32. J Neurochem. 2000;75:248-257.

34. Zachariou V, Sgambato-Faure V, Sasaki T, et al. Phosphorylation of DARPP-32 at threonine-34 is required for cocaine action. Neuropsychopharmacology. 2006;31:555-562.

35. Marais R, Wynne J, Treisman R. The SRF accessory protein Elk-1 contains a growth factor-regulated transcriptional activation domain. Cell. 1993;73:381-393.

36. Santini E, Valjent E, Fisone G. Parkinson's disease: levodopa-induced dyskinesia and signal transduction. FEBS J. 2008;275:1392-1399.

\section{Publish your work in this journal}

Neuropsychiatric Disease and Treatment is an international, peerreviewed journal of clinical therapeutics and pharmacology focusing on concise rapid reporting of clinical or pre-clinical studies on a range of neuropsychiatric and neurological disorders. This journal is indexed on PubMed Central, the 'PsycINFO' database and CAS.
The manuscript management system is completely online and includes a very quick and fair peer-review system, which is all easy to use. Visit http://www.dovepress.com/testimonials.php to read real quotes from published authors.

Submit your manuscript here: http://www.dovepress.com/neuropsychiatric-disease-and-treatment-journal 